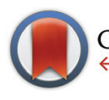

CrossMark \& click for updates

Cite this: Dalton Trans., 2015, 44 7548

Received 4th February 2015,

Accepted 9th March 2015

DOI: $10.1039 / c 5 d t 00521 \mathrm{c}$

www.rsc.org/dalton

\section{Exploring a novel preparation method of 1D metal organic frameworks based on supercritical $\mathrm{CO}_{2} \dagger$}

\author{
A. López-Periago, ${ }^{\star a}$ O. Vallcorba, ${ }^{b}$ C. Frontera, ${ }^{a}$ C. Domingo ${ }^{a}$ and J. A. Ayllón ${ }^{\star c}$ \\ The preparation of copper(I) one-dimensional MOFs using an eco-efficient method is reported here. This \\ method is based exclusively on using supercritical $\mathrm{CO}_{2}$ as a solvent, without the addition of any other \\ additive or co-solvent. Neutral acetylacetonate copper complexes and two linear linkers, namely, the \\ bidentate 4,4'-bipyridine and 4,4'-trimethylenedipyridine molecules, were reacted under compressed \\ $\mathrm{CO}_{2}$ at $60^{\circ} \mathrm{C}$ and $20 \mathrm{MPa}$ for periods of 4 or $24 \mathrm{~h}$. The success achieved in the synthesis of the different \\ studied $1 \mathrm{D}$-MOFs was related to the solubility of the reagents in supercritical $\mathrm{CO}_{2}$. The reaction yield of \\ the synthesized coordination polymers via the supercritical route was close to $100 \%$ because both the \\ reactants were almost completely depleted in the performed experiments.
}

\section{Introduction}

Metal organic frameworks (MOFs) are comprised of metal and multidentate organic units, which are linked together to form an infinite array through an extended covalent or coordinative interaction. ${ }^{1}$ MOFs are a special type of crystalline hybrid materials that are broadly studied because they have an enormous potential of forming one (1D), two (2D) and three (3D) dimensional architectures. Specific features, such as the metal used, the size and the structure of the ligands or the steric hindrance, would induce a large variety of properties in the designed MOFs, ranging from inertness to very reactive products.

An unlimited collection of feasible MOF structures have been described for a large range of applications in the areas of molecular electronics, magnetism, chemical sensing, catalysis and gas adsorption. ${ }^{2}$ 2D and 3D-MOFs are often synthesized with large surface areas, in the order of several hundred to several thousand square meters per gram, and they have attracted massive attention as candidate materials for gas adsorption, separation and storage. Conversely, the unusual properties of coordination metal complexes with 1D polymeric structures confer their usage as molecular ferromagnets, superconducting polymers, linear optical materials or ferroelectric compounds. ${ }^{3}$ Moreover, the high metal content in

\footnotetext{
${ }^{a}$ Instituto de Ciencia de Materiales de Barcelona (CSIC), Campus UAB, 08193 Bellaterra, Spain. E-mail: amlopez@icmab.es

${ }^{b} A L B A$ Synchrotron Light Source, Cerdanyola del Vallés, Barcelona, Spain

${ }^{c}$ Departament de Quimica, Universitat Autònoma de Barcelona, Campus UAB,

Bellaterra, Spain. E-mail: joseantonio.ayllon@uab.cat

$\dagger$ Electronic supplementary information (ESI) available. CCDC 1051509. For ESI and crystallographic data in CIF or other electronic format see DOI: 10.1039/ c5dt00521c
}

MOFs and their high thermal and mechanical stability, together with their insolubility in water and common organic solvents, make them excellent candidates for heterogeneous catalytic processes, for example, the use of some copper(II)based MOFs with Lewis acid sites for the transformation of organic molecules. ${ }^{4,5}$

The synthesis method plays an important role in defining the final MOF composition and structure. Most of the MOFs are synthesized by the solvothermal route under autogenous pressure and temperatures above the boiling point of the used organic solvent. ${ }^{6,7}$ Some prominent MOFs have also been obtained at room temperature by mixing the starting reagents previously dissolved in an appropriate medium. ${ }^{8}$ Solvents are often incorporated in the synthesized MOFs, which act as space-filling molecules and define the structure of the final product. In regards to more environmentally friendly solvent techniques, microwave assisted, electrochemical and sonochemical approaches have been developed. ${ }^{9,10}$ Mechanochemistry, which is also considered as a green chemistry approach, produces MOFs just by grinding an organic linker with a metal containing precursor. Although it is considered as a solid-state process, the use of small quantities of solvent is often included in the protocol to enhance the yield or to control the nature of the final product. ${ }^{11}$

The main goal of this work was the development of an effective and eco-friendly procedure for the synthesis of 1D-MOFs by exclusively using supercritical carbon dioxide $\left(\mathrm{scCO}_{2}\right)$ as a solvent. To date, aside from the very limited reports that address the kinetics of the formation of copper(II) coordination complexes in $\mathrm{scCO}_{2},{ }^{12}$ the use of this solvent in the field of MOFs processing has been limited to the postsynthesis activation by the cleansing of entrapped undesirable by-products or solvents. ${ }^{13,14}$ Copper(II) metal complexes and 
linear ligands, particularly the bidentate $4,4^{\prime}$-bipyridine and $4,4^{\prime}$-trimethylenedipyridine, ${ }^{15}$ have been chosen for analysis. The physicochemical and textural properties of the prepared samples were measured and compared against those prepared by a conventional solvent method.

\section{Experimental}

\section{Materials}

Neutral copper(II) building blocks: $\mathrm{Cu}(\mathrm{hfacac})_{2}$ (copper hexafluoroacetylacetonate), $\mathrm{Cu}(\mathrm{tfacac})_{2}$ (copper trifluoroacetylacetonate) and $\mathrm{Cu}(\mathrm{acac})_{2}$ (copper acetylacetonate) were chosen as the metal complexes (Fig. 1). 4,4'-Bipyridine (bpy) and 4,4'-trimethylenedipyridine (tpy) were used in the synthesis as ligands (Fig. 1). For the conventional synthesis protocol, dichloromethane (DCM) was used as a solvent. Reagents and liquid solvents were all purchased from Sigma Aldrich and used without further purification. For a supercritical procedure, the compressed $\mathrm{CO}_{2}$ used (99.995\%) was supplied by Carburos Metálicos S.A., Air Products Group (Spain).

\section{Synthetic procedures}

Supercritical method. Sample preparation under $\mathrm{scCO}_{2}$ was carried out in a $100 \mathrm{~mL}$ batch high pressure reactor (TharDesign), which is described elsewhere. ${ }^{16}$ The autoclave was charged with $c a .150-200 \mathrm{mg}$ of a copper(II) complex and, predominantly, an equimolar amount of ligand (Table 1). The
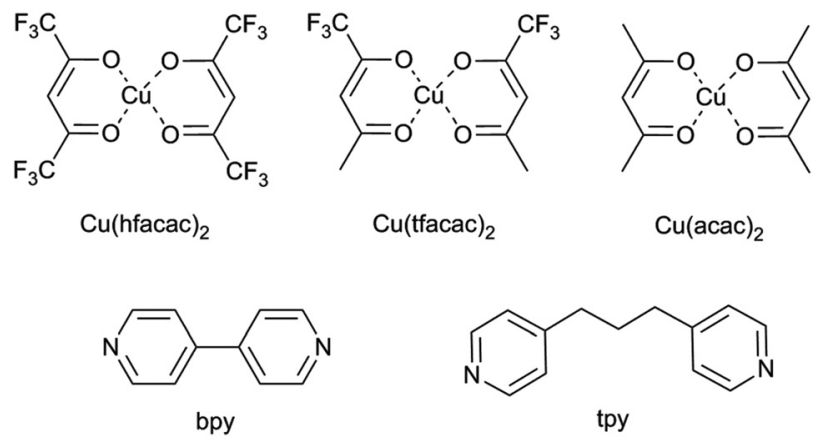

\section{$\mathrm{Cu}(\text { acac })_{2}$}

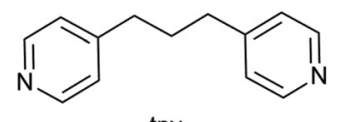

tpy

Fig. 1 Structures of the used reagents: metal complexes (namely, Cu(hfacac) $)_{2}, \mathrm{Cu}(\mathrm{tfacac})_{2}$, and $\mathrm{Cu}(\mathrm{acac})_{2}$ ) and organic linkers (namely, bpy and tpy).

Table 1 Samples prepared following the supercritical procedure, indicating the added metal: ligand $(\mathrm{m}: \mathrm{L})$ mole ratio and reaction time, as well as the measured $m: L$ ratio in the end product

\begin{tabular}{llll}
\hline Sample & $\begin{array}{l}\text { Added } \\
\mathrm{m}: \mathrm{L} \text { ratio }\end{array}$ & $\begin{array}{l}\text { Reaction } \\
\text { time }[\mathrm{h}]\end{array}$ & $\begin{array}{l}\text { Product } \\
\mathrm{m}: \mathrm{L} \text { ratio }\end{array}$ \\
\hline$\left[\mathrm{Cu}(\mathrm{hfacac})_{2} \mathrm{tpy}\right]_{n}$-sc & $1: 1$ & 4 & $1: 1$ \\
{$\left[\mathrm{Cu}(\mathrm{hfacac})_{2} \mathrm{bpy}\right]_{n}$-sc } & $1: 1$ & 4 & $1: 1$ \\
{$\left[\left\{\mathrm{Cu}(\mathrm{tfacac})_{2}\right\}_{x} \mathrm{bpy}\right]_{y}$-sc } & $1: 1$ & 4 & Mixture \\
{$\left[\mathrm{Cu}(\mathrm{tfacac})_{2} \mathrm{bpy}\right]_{n}$-sc } & $1: 2$ & 24 & $1: 1$ \\
{$\left[\mathrm{Cu}(\mathrm{acac})_{2} \mathrm{bpy}\right]_{n}$ and reagents } & $1: 1$ & 24 & Mixture \\
{$\left[\mathrm{Cu}(\mathrm{acac})_{2} \mathrm{bpy}\right]_{n}$-sc } & $1: 1$ & 4 (stirring) & $1: 1$
\end{tabular}

physical contact between the two reagents was avoided by placing them in two separate Pyrex vials inside the autoclave. The autoclave was electrically heated with resistances and pressurized with a syringe pump (Teledyne Isco Model 260D). Supercritical experiments were carried out under the standard conditions of $20 \mathrm{MPa}$ and $60^{\circ} \mathrm{C}$ during a reaction time of $4 \mathrm{~h}$, which was increased to $24 \mathrm{~h}$ when necessary. Experiments were performed without using stir bars for agitation to prevent any mechanochemical effects. However, for the $\mathrm{Cu}(\mathrm{acac})_{2}$ metal complex, with the lowest solubility in $\mathrm{scCO}_{2}$, gentle stirring was applied to the vial that contained the metal to increase the kinetics of the process. In a separate test, which was performed under ambient conditions and in the absence of $\mathrm{CO}_{2}$, it was confirmed that the agitation used did not cause any mechanochemical effect. At the end of each experiment, the system was slowly depressurized and allowed to cool to room temperature.

Conventional method. For comparative reasons, a conventional liquid approach was investigated to synthesize the products that have not been previously reported in the literature. In this procedure, the metal complex and the ligand were dissolved separately in DCM, and then the obtained solutions were mixed in a $1: 1$ metal: ligand molar ratio at room temperature. The resulting precipitate was filtered and further dried at $45{ }^{\circ} \mathrm{C}$ in a hot air oven.

\section{Characterization}

The products were obtained as green crystalline powders, which made it possible to study them by powder X-ray diffraction (XRD, with a Siemens D5000) using the $\mathrm{Cu} \mathrm{K} \alpha$ incident radiation. The diffraction patterns were recorded from $2 \theta=5^{\circ}$ to $50^{\circ}$ with a step scan of $0.02^{\circ}$ counting for $1 \mathrm{~s}$ at each step. For the products in which the crystal structure was known, powder XRD patterns were analyzed by the Le Bail method. ${ }^{17}$ The background was described by an interpolation of fixed (not refined) points and a peak profile was described by a pseudo-Voigt function. Zero-error, cell parameters, profile parameters and peak asymmetry were refined. Moreover, the crystal structure of one of these products, namely, $[\mathrm{Cu}(\mathrm{hfa}-$ cac) $)_{2}$ bpy $]_{n}$, could be determined after collecting synchrotron powder X-ray diffraction data in the MSPD Beamline of ALBA Synchrotron using the microstrip MYTHEN-II detector $(\lambda=$ $0.61978 \AA$ Å). The powder pattern was indexed using DICVOL04, ${ }^{18}$ and the further refinement of cell parameters, space group identification and intensity extraction were performed with DAJUST software. ${ }^{19}$ Extracted intensities were used in the directspace strategy TALP ${ }^{20}$ to solve the crystal structures using a previously reported structure ${ }^{21}$ of $\left[\mathrm{Cu}(\mathrm{tfacac})_{2} \mathrm{bpy}\right]_{n}$ as a starting model to generate geometrical restraints. A Rietveld refinement of the obtained solution gave the final crystal structure of the compound. Crystallographic data, refinement details, Hirshfeld surface with $d_{\text {norm }}$ as a mapped property (Fig. S1 $\dagger$ ) and CIF file are included in the ESI.

The weight percentage of organic atoms in the obtained samples was estimated by the elemental analysis of $\mathrm{C}, \mathrm{H}$ and $\mathrm{N}$ using a Flash EA2000 Thermo Fisher Scientific analyzer. 
Textural properties were determined by $\mathrm{N}_{2}$ adsorption at $77 \mathrm{~K}$ by applying the BET method using an ASAP 2000 Micromeritics INC. Samples were first degassed at $60{ }^{\circ} \mathrm{C}$ for $24 \mathrm{~h}$. Morphological features were examined by scanning electron microscopy (SEM) with a Hitachi S570 apparatus.

\section{Results and discussion}

Taking into account the common solvating properties of $\mathrm{scCO}_{2}$, neutral copper(II) acetylacetonates complexes with different degrees of fluorination were chosen as building blocks (Fig. 1). These compounds have a significant solubility in this supercritical fluid, which is determined by the fluoride content and categorized as $\mathrm{Cu}(\mathrm{acac})_{2}<\mathrm{Cu}(\mathrm{tfacac})_{2}<\mathrm{Cu}(\mathrm{hfacac})_{2}{ }^{22}$ Under working experimental conditions, organic linkers were totally soluble in $\mathrm{scCO}_{2}$. For the metal complexes, solubility values, reported at $40{ }^{\circ} \mathrm{C}$ and $10-30 \mathrm{MPa}$, are in the order of $0.7-2.3 \times 10^{-5}, 2.9-5.9 \times 10^{-4}$ and 6.1-7.4 $\times 10^{-4}$ mole fraction for $\mathrm{Cu}(\mathrm{acac})_{2}, \mathrm{Cu}(\mathrm{tfacac})_{2}$ and $\mathrm{Cu}(\mathrm{hfacac})_{2}$, respectively. ${ }^{23}$

Reaction yield in the described supercritical procedure was very high because both reactants were almost completely depleted in the performed experiments. Moreover, the postreaction steps of solvent elimination involving filtration and drying, which are necessary to obtain a pure product following the conventional solvent procedure, were eliminated in the supercritical synthesis protocol. In fact, the compressed $\mathrm{CO}_{2}$ is eliminated as a gas during depressurization. This fact not only increases the process yield, but also considerably reduces the processing time for each experimental batch.

As a part of an ongoing work, the six possible reactions between bipyridyl ligands and copper(II) acetylacetonate derivatives, shown in Fig. 1 , are being surveyed under $\mathrm{scCO}_{2}$ conditions. Nevertheless, in this article, only data corresponding to four selected combinations are presented (Table 1), corresponding to the three studied metal complexes, namely, $\mathrm{Cu}(\text { hfacac })_{2}, \mathrm{Cu}(\text { tfacac })_{2}$ and $\mathrm{Cu}(\mathrm{acac})_{2}$, reacted with 4,4'-bipyridine, and the $\mathrm{Cu}(\text { hfacac })_{2}$ reagent combined with 4,4'trimethylenedipyridine. The chosen species were either previously described in the literature or could be clearly characterized with regard to the stoichiometry. The reaction between $\mathrm{Cu}(\mathrm{tfacac})_{2}$ or $\mathrm{Cu}(\mathrm{acac})_{2}$ with 4,4'-trimethylenedipyridine in $\mathrm{scCO}_{2}$ have also been tested. However, complex product mixtures, which were difficult to characterize, were obtained. The experimental conditions required to obtain pure products are currently under investigation.

The measured weight percentages of $\mathrm{C}, \mathrm{H}$ and $\mathrm{N}$ in each prepared sample are given in the Table 2, together with the theoretically calculated values.

The textural properties of the selected synthesized products were studied by low temperature $\mathrm{N}_{2}$ adsorption isotherms. In accordance with results obtained by other authors, the crystallized 1D-MOFs exhibited a very low BET surface area, in the range of $5-10 \mathrm{~m}^{2} \mathrm{~g}^{-1},{ }^{24,25}$ in comparison to 3D-MOFs reported in the literature with surface areas as high as $7000 \mathrm{~m}^{2} \mathrm{~g}^{-1} \cdot{ }^{26}$ The average pore diameter was between 5 and $10 \mathrm{~nm}$, while
Table 2 Theoretically calculated and experimentally measured $\mathrm{C}, \mathrm{H}$ and $\mathrm{N}$ weight percentages for the synthesized samples either by the supercritical or conventional route in $\mathrm{scCO}_{2}$ or $\mathrm{DCM}$, respectively

\begin{tabular}{llrrr}
\hline Sample & Atom & Theor. [\%] & scCO $_{2}[\%]$ & DCM [\%] \\
\hline$\left[\mathrm{Cu}(\text { hfacac })_{2} \mathrm{tpy}\right]_{n}$ & $\mathrm{C}$ & 40.87 & 40.91 & 41.17 \\
& $\mathrm{H}$ & 2.39 & 2.37 & 2.60 \\
& $\mathrm{~N}$ & 4.14 & 4.02 & 4.01 \\
{$\left[\mathrm{Cu}(\mathrm{hfacac})_{2} \mathrm{bpy}\right]_{n}$} & $\mathrm{C}$ & 37.90 & 38.03 & - \\
& $\mathrm{H}$ & 1.59 & 1.62 & - \\
& $\mathrm{N}$ & 4.43 & 4.59 & - \\
{$\left[\mathrm{Cu}(\mathrm{tfacac})_{2} \mathrm{bpy}\right]_{n}$} & $\mathrm{C}$ & 45.68 & 45.54 & 46.04 \\
& $\mathrm{H}$ & 3.07 & 3.18 & 3.15 \\
& $\mathrm{~N}$ & 5.32 & 5.20 & 5.13 \\
{$\left[\mathrm{Cu}(\mathrm{acac})_{2} \mathrm{bpy}\right]_{n}$} & $\mathrm{C}$ & 57.48 & 56.15 & - \\
& $\mathrm{H}$ & 5.31 & 5.32 & - \\
& $\mathrm{N}$ & 6.70 & 6.20 & -
\end{tabular}

the pore volume was in the order of $0.01 \mathrm{~cm}^{3} \mathrm{~g}^{-1}$. Based on the IUPAC classification, these results indicate the formation of mesoporous solids. According to the small values of pore volume and surface area, these values are ascribed to adsorption only at the external surface of the precipitated crystals. As a consequence, these materials should not be considered for adsorption applications. However, 1D-MOFs find uses in other important technological applications such as heterogeneous catalysis, magnetic devices, and linear optics and so on. ${ }^{3-5}$

$\left[\mathrm{Cu}(\text { hfacac })_{2} \text { ligand }\right]_{n}$ coordination polymers. The high solubility of the fully fluorinated $\mathrm{Cu}$ (hfacac) $)_{2}$ complex in $\mathrm{scCO}_{2}$ (ca. $6.5 \times 10^{-4}$ mole fraction under working conditions ${ }^{23}$ ) facilitated the straightforward preparation of $1: 1$ coordination polymers by its reaction with any of the two bipyridyl ligands studied in this work (Table 1). From them, only the [Cu(hfacac $)_{2}($ tpy $\left.)\right]_{n}$ product has been described in the literature, which was prepared as a single crystal from a DCM solution. ${ }^{27,28}$ This structure is described as octahedral coordinated copper(II) centres linked by a 4,4'-trimethylene-dipyridine ligand adopting a cis-trans geometry. ${ }^{28}$

The elemental analysis of the synthesized $\left[\mathrm{Cu}(\mathrm{hfacac})_{2} \mathrm{tpy}\right]_{n^{-}}$ sc sample (Table 2) was coincident with the theoretically calculated value for an equimolar polymer structure. The crystallographic data of the $\left[\mathrm{Cu}(\mathrm{hfacac})_{2}\right.$ tpy $\left.)\right]_{n}$ sample in ref. $27[P c$ space group and $a=7.9502(5) \AA, b=9.6866(6) \AA, c=$ $\left.18.5732(10) \AA, \beta=95.8090(10)^{\circ}\right]$ was used as the starting point for the Le Bail refinement (Fig. 2 and S2 $\dagger$ ). The refined lattice parameters were $a=7.978$ (3) ̊, $b=9.678(2) \AA, c=18.607$ (4) $\AA$, and $\beta=95.56(4)^{\circ}$, which fairly coincided with those reported in the abovementioned reference $[\Delta a / a=0.003, \Delta b / b=-0.001$, $\Delta c / c=0.002$, and $\Delta \beta /(\beta-90)=0.04]$. In addition, just a few low intense peaks did not correspond to the $\left[\mathrm{Cu}(\mathrm{hfacac})_{2}(\text { tpy) }]_{n}\right.$ phase, thus proving that only a very small percentage of impurities appears in addition to this compound, as suggested by the elemental analysis. 


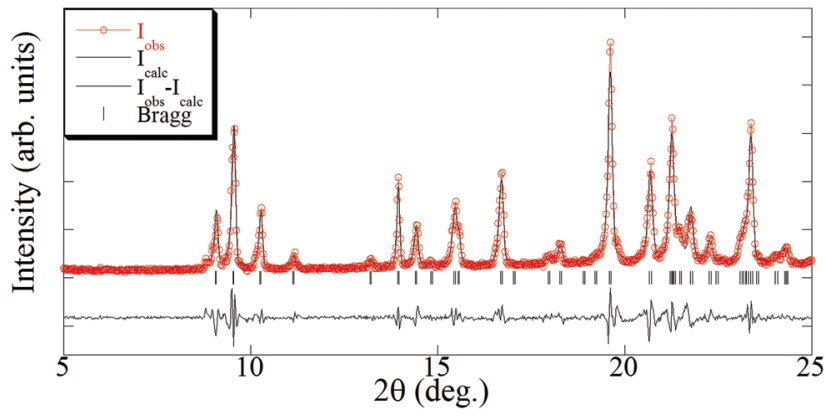

Fig. 2 Final Le Bail whole pattern decomposition plot for the [Cu(hfacac) ${ }_{2}$ tpy $]_{n}$-sc sample.

The supercritically precipitated product adopted the form of platelet-like microcrystals with a submicrometric thickness, as observed in the morphological analysis of this sample performed by SEM (Fig. 3).

In contrast to the $\left[\mathrm{Cu}(\mathrm{hfacac})_{2} \mathrm{tpy}\right]_{n}$ product, the structure of the $\left[\mathrm{Cu}(\mathrm{hfacac})_{2} \mathrm{bpy}\right]_{n}$ polymer has not been described in the literature. For this material, the supercritically synthesized sample was compared with the equivalent material obtained by the conventional procedure. The diffraction patterns of analogous compounds obtained using both the synthesis routes are compared in Fig. 4. Similar diffraction angles were
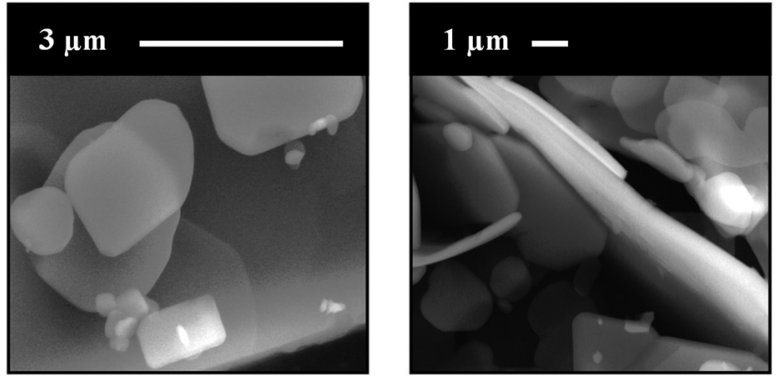

Fig. 3 SEM micrographs of the supercritically precipitated [Cu(hfacac) ${ }_{2}$ tpy $]_{n}$-sc polymer at two different magnifications.

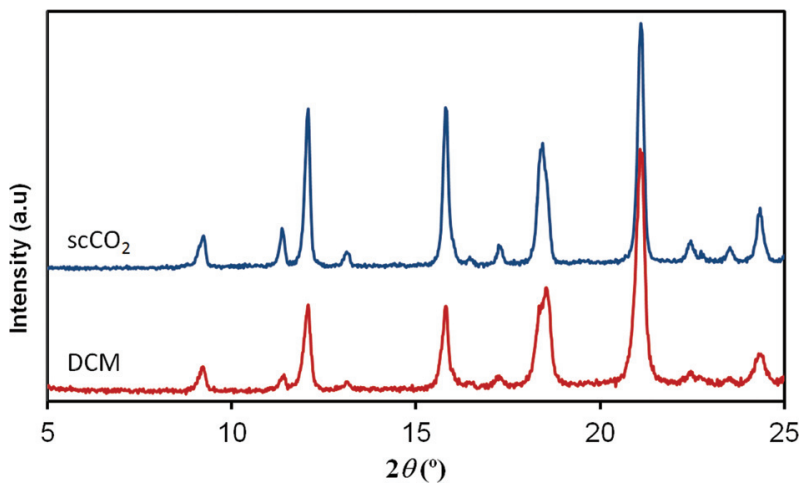

Fig. 4 XRD patterns of $\left[\mathrm{Cu}(\text { hfacac })_{2} \text { bpy }\right]_{n}$ prepared using $\mathrm{scCO}_{2}$ and compared to the DCM synthesized equivalent material. measured for the materials prepared by DCM and $\mathrm{ScCO}_{2}$. Though a slight divergence related to the relative intensities of recorded peaks was observed, it was attributed to the texture and the distribution of the crystallographic preferred orientations in the polycrystalline samples. Furthermore, the elemental analysis also supported the finding that the $\mathrm{Cu}(\text { hfacac })_{2}$ metal complex combined in an equimolar ratio with 4,4'-bipyridine. Similar results were obtained for the conventionally precipitated polymer (Table 2 ).

The crystal structure of $\left[\mathrm{Cu}(\text { hfacac })_{2} \text { bpy }\right]_{n}$ has been solved from synchrotron powder diffraction data. The compound crystallizes in the tetragonal $P 4_{1} 2_{1} 2$ space group [lattice parameters are $a=b=7.882(2) \AA, c=38.0767(7) \AA$, vol = 2369.3(1) $\left.\AA^{3}\right]$, and no other crystalline phases (impurities) are present in the pattern. The main feature of the structure is the Cu-bpy chain that gives rise to the 1D-MOF propagation (Fig. 5). The propagation of the chain is along two directions, namely, $\left[\begin{array}{lll}1 & 1 & 0\end{array}\right]$ and $\left[\begin{array}{lll}1 & -1 & 0\end{array}\right]$, due to the $4_{1}$ screw axis that changes the relative orientation of the chain along the $c$ parameter. There is no relevant intermolecular interaction between the chains. Rietveld plot with observed, calculated and difference profile is shown in Fig. 6.

$\left[\mathrm{Cu}(\mathrm{tfacac})_{2} \mathrm{bpy}\right]_{n}$ coordination polymer. In comparison to the other two copper(II) complexes used in this work, the copper salt $\mathrm{Cu}(\mathrm{tfacac})_{2}$ presents an intermediate solubility in $\mathrm{scCO}_{2}$ (ca. $4.0 \times 10^{-4}$ mole fraction under working con-
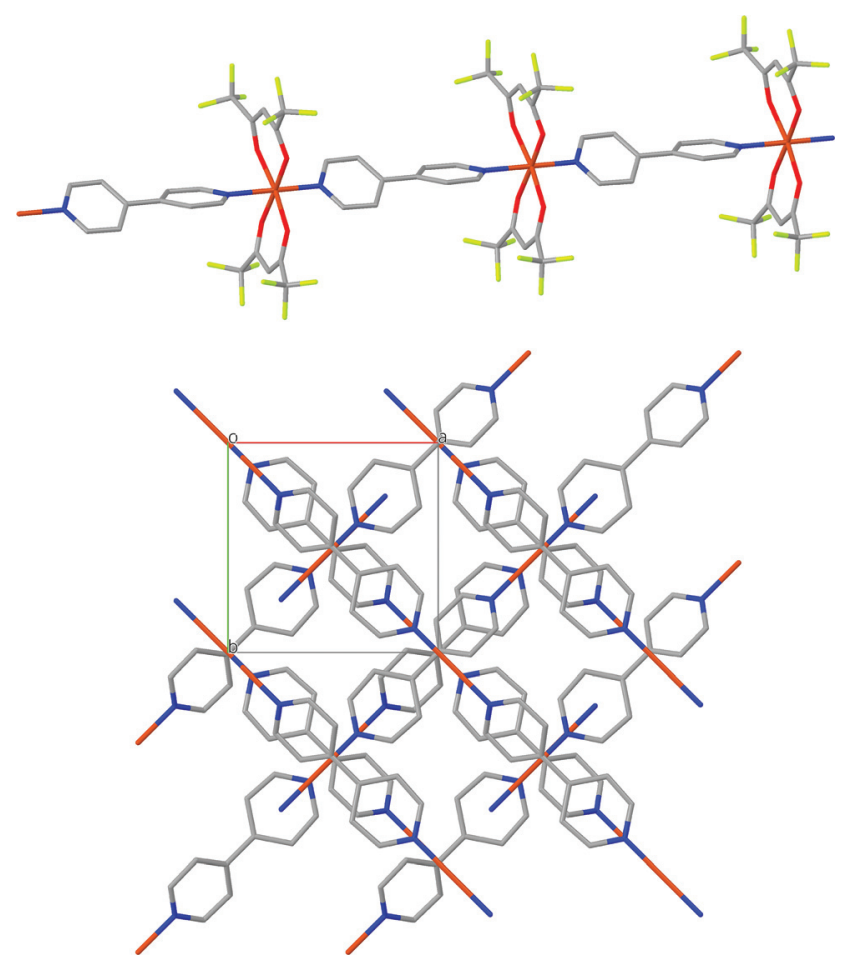

Fig. 5 (top) Polymeric chains in the crystal structure of $\left[\mathrm{Cu}(\mathrm{hfacac})_{2}-\right.$ bpy $]_{n}$ ( $\mathrm{H}$-atoms have been omitted) and (bottom) propagation of the chains along the [110] and [1-10] directions. The hfacac ligand has been omitted for clarity. 


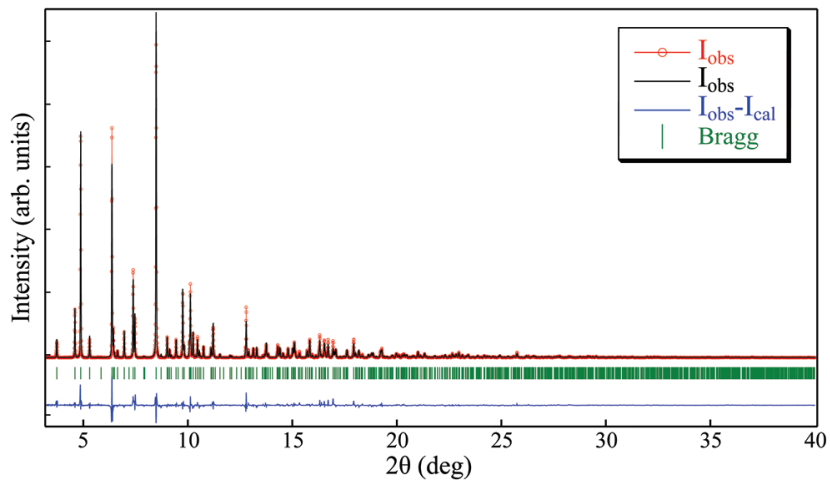

Fig. 6 Rietveld plot with observed, calculated and difference profile for $\left[\mathrm{Cu}(\mathrm{hfacac})_{2} \mathrm{bpy}\right]_{n}$ material.

ditions ${ }^{23}$ ). This metal complex was reacted in a $1: 1$ molar ratio with the 4,4'-bipyridine ligand under the $\mathrm{scCO}_{2}$ standard conditions, which were previously used to form the $\mathrm{Cu}$ (hfacac) $)_{2}$ : ligand materials (Table 1). As a result, a mixture of two products was obtained, which was identified as the expected $\left[\mathrm{Cu}(\mathrm{tfacac})_{2} \mathrm{bpy}\right]_{n}$ coordination polymer along with a second compound, whose exact nature is currently under study. To precipitate solely the equimolar coordination polymer, it was necessary to increase the relative amount of 4,4'-bipyridine to a $1: 2$ metal : ligand molar ratio, and to use a longer reaction time of $24 \mathrm{~h}$ (Table 1). Under these experimental conditions, the elemental analysis showed that the equimolar polymer, represented by the $\left[\mathrm{Cu}(\mathrm{tfacac})_{2} \mathrm{bpy}\right]_{n}$-sc sample, was exclusively obtained (Table 2). The close match in the $1: 1$ stoichiometry indicated a high degree of purity for the supercritically synthesized polymer, which could be easily attained due to the high solubility of $4,4^{\prime}$-bipyridine in $\mathrm{scCO}_{2}$. The added excess of ligand was eliminated during depressurization without the need of a further cleaning step. The 1D polymer $\left[\mathrm{Cu}(\mathrm{tfacac})_{2} \mathrm{bpy}\right]_{n}$ has been described in the literature, which has been synthesized by either mechanochemistry ${ }^{29}$ or liquid phase. ${ }^{21}$ Thus, for the $\left.\left[\mathrm{Cu}(\mathrm{tfacac})_{2} \mathrm{bpy}\right)\right]_{n}$-sc sample, the crystallographic information obtained from ref. 21 [Pnnm space group and $a=8.3790(10) \AA, b=8.3790(10) \AA$, and $c=$ 15.832(4) $\AA$ ] was used as the starting point for Le Bail fitting of the XRD pattern (Fig. 7 and S3 $\dagger$ ). Lattice parameters found $[a=$ 8.405(4) $\AA$, $b=8.405(4) \AA$, and $c=15.842(8) \AA]$ were in good agreement with the reported ones $(\Delta a / a=0.003, \Delta b / b=0.003$, and $\Delta c / c=0.001)$. In addition to the diffraction peaks corresponding to this phase, only small additional peaks were observed, which evidenced again that impurities were present only in a very small percentage.

$\left[\mathrm{Cu}(\mathbf{a c a c})_{2} \mathbf{b p y}\right]_{n}$ coordination polymer. The complex Cu(acac) $)_{2}$ has the lowest solubility in $\mathrm{scCO}_{2}\left(c a .1 .5 \times 10^{-5}\right.$ mole fraction under working conditions ${ }^{23}$ ) among the three studied metal complexes, which would reduce the driving force for the metal to react with the ligand. This product was mixed with $4,4^{\prime}$-bipyridine and allowed to react under the standard supercritical reaction conditions for $24 \mathrm{~h}$. Even with this prolonged reaction time, the recovered product was a mixture of

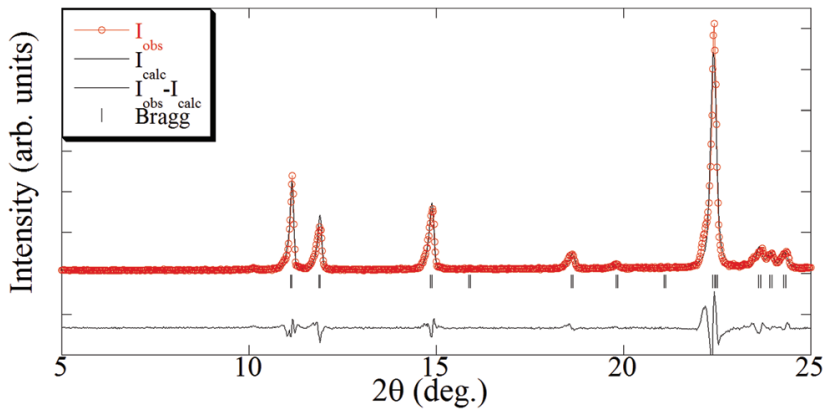

Fig. 7 Final Le Bail whole pattern decomposition plot of [Cu(tfacac $)_{2^{-}}$ bpy $]_{n}$-sc sample.

$\left[\mathrm{Cu}(\mathrm{acac})_{2} \mathrm{bpy}\right]_{n}$ and residual reagents, indicating very slow reaction kinetics. For this product, the reaction rate in $\mathrm{scCO}_{2}$ was enhanced by smoothly agitating the vial that contained the metal complex. In this case, the complete reaction of the precursors occurred and the elemental analysis suggested that an equimolar polymer was obtained (Table 2). It has been described in the literature that $\left[\mathrm{Cu}(\mathrm{acac})_{2} \mathrm{bpy}\right]_{n}$ can be produced by refluxing an equimolar ratio of the reagents in chloroform for a long period of time, ${ }^{30}$ while the mechanochemical approach needed an excess of ligand. ${ }^{29}$

The Le Bail method for $\left[\mathrm{Cu}(\mathrm{acac})_{2} \mathrm{bpy}\right]_{n}$-sc (Fig. 8 and $\mathrm{S} 4 \dagger$ ) was applied in this sample starting with the crystallographic information provided in ref. $30\left[P 2_{1} / n\right.$ space group and $a=$ 11.2162(3) ̊, $b=14.3523(7) \AA, c=11.9411(7) \AA$, and $\beta=$ $\left.92.987(4)^{\circ}\right]$. The fitting procedure rendered the following cell parameters: $a=11.366(3) \AA, b=14.583(4) \AA, c=12.051(4) \AA$, and $\beta=94.19(4)^{\circ}$, which presented a discrepancy with the reported values $[\Delta a / a=0.01, \Delta b / b=-0.02, \Delta c / c=0.001$, and $\Delta \beta /(\beta-90)=0.4]$. These values were slightly larger than those for the other compounds presented in this work. To further ensure that the synthesized compound corresponded to the $\left[\mathrm{Cu}(\mathrm{acac})_{2} \mathrm{bpy}\right]_{n}$ coordination polymer, a Rietveld refinement of the measured pattern was performed by keeping the structure in ref. 30 fixed (Fig. $55 \dagger$ ). The refinement rendered good agreement parameters $\left(R_{\mathrm{B}}=11 \%\right.$, and $\left.\chi^{2}=5.2\right)$, which confirmed that the phase formed was very similar to that reported in the

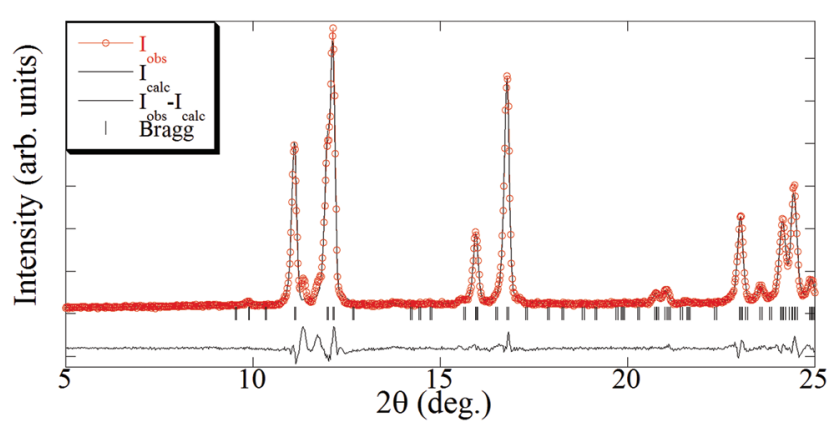

Fig. 8 Final Le Bail whole pattern decomposition plot of $\left[\mathrm{Cu}(\mathrm{acac})_{2^{-}}\right.$ bpy $]_{n}$-sc sample. 
literature. Only tiny diffraction peaks remained, which were not reproduced by both the procedures (namely, Le Bail and Rietveld), indicating the presence of a small amount of impurities in addition to the main phase. This small amount of impurities accounts for the discordance between the experimental and theoretical values observed in the elemental analysis for this sample (Table 2).

\section{Conclusions}

The results obtained from the reaction between the studied copper(II) metal complexes and two different bipyridyl organic ligands carried out in $\mathrm{scCO}_{2}$ have demonstrated that this method can be used to prepare 1D-MOFs held together by axial $\mathrm{Cu}-\mathrm{N}$ bonds, giving rise to highly crystalline products. A key factor that influences the formation of the desired product was the different solubility of the metal reagents in $\mathrm{scCO}_{2}$. Indeed, 1D coordination polymers were easily formed using the highly $\mathrm{scCO}_{2}$ soluble metal complex, namely, $\mathrm{Cu}$ (hfacac) $)_{2}$, which readily reacted with the two bipyridyl ligands studied in this work to give equimolar products. A characteristic advantage of using $\mathrm{scCO}_{2}$ as the solvent to synthesize $1 \mathrm{D}-\mathrm{MOF}$ is related to the greener properties of $\mathrm{CO}_{2}$ in comparison with most organic solvents. Moreover, the lack of reactivity of this solvent with most of the reagents, including the $\mathrm{N}$ atom in the bipyridyl ligands, is remarkable. In this respect, we believe that this work establishes a solid foundation for further investigations in the synthesis of more complex 2D and 3D-MOFs structures with $\mathrm{ScCO}_{2}$.

\section{Acknowledgements}

This work was partially financed by EU COST project MP1202 OC-2011-2-10820 and by the Generalitat de Catalunya 2014SGR377. A. López-Periago acknowledges the RyC-201211588 contract. ALBA synchrotron is acknowledged for the provision of beam time.

\section{Notes and references}

1 A. K. Cheetham, C. N. R. Rao and R. K. Feller, Chem. Commun., 2006, 4780.

2 A. U. Czaja, N. Trukhan and U. Muller, Chem. Soc. Rev., 2009, 38, 1284.

3 C.-T. Chen and K. S. Suslick, Coord. Chem. Rev., 1993, 128, 293.

4 S. J. Singh, S. R. Kale, M. B. Gawande, A. Velhinho and R. V. Jayaram, Catal. Commun., 2014, 44, 24.

5 Y. Zhao, D.-S. Deng, L.-F. Ma, B.-M. Ji and L.-Y. Wang, Chem. Commun., 2013, 49, 10299.
6 C. Dey, T. Kundu, B. P. Biswal, A. Mallick and R. Banerjee, Acta Crystallogr., Sect. B: Struct. Sci., 2014, 70, 3.

7 P. Pachfule, R. Das, P. Poddar and R. Banerjee, Cryst. Growth Des., 2011, 11, 1215.

8 D. Tranchemontagne, J. Hunt and O. M. Yaghi, Tetrahedron, 2008, 64, 8553.

9 N. Stock and S. Biswas, Chem. Rev., 2012, 112, 933.

10 D.-W. Jung, D. A. Yang, J. Kim, J. Kim and W.-S. Ahn, Dalton Trans., 2010, 39, 2883.

11 S. L. James, C. J. Adams, C. Bolm, D. Braga, P. Collier, T. Friščić, F. Grepioni, K. D. M. Harris, G. Hyett, W. Jones, A. Krebs, J. Mack, L. Maini, G. Orpen, I. P. Parkin, W. C. Shearouse, J. W. Steed and D. C. Waddell, Chem. Soc. Rev., 2012, 41, 413.

12 Y. Inada, T. Horita, Y. Yokooka and S. Funahashi, J. Supercrit. Fluids, 2004, 31, 175.

13 A. P. Nelson, O. K. Farha, K. L. Mulfort and J. T. Hupp, J. Am. Chem. Soc., 2009, 131, 458.

14 B. Liu, A. G. Wong-Foy and A. J. Matzger, Chem. Commun., 2013, 49, 1419.

15 K. Biradha, M. Sarkar and L. Rajput, Chem. Commun., 2006, 4169.

16 A. M. Lopez-Periago, C. A. Garcia-Gonzalez and C. Domingo, Chem. Commun., 2010, 46, 4315.

17 J. Rodríguez-Carvajal, Phys. Rev. B: Condens. Matter, 1993, 192, 55.

18 A. Boultif and D. Louer, J. Appl. Crystallogr., 2004, 37, 724.

19 O. Vallcorba, J. Rius, C. Frontera, I. Peral and C. Miravitlles, J. Appl. Crystallogr., 2012, 45, 44.

20 O. Vallcorba, J. Rius, C. Frontera and C. Miravitlles, J. Appl. Crystallogr., 2012, 45, 1270.

21 K. B. Yu, S. H. Gou, X. Z. You and Z. Xu, Acta Crystallogr., Sect. C: Cryst. Struct. Commun., 1991, 47, 2653.

22 W. H. Teoh, R. Mammucari and N. R. Foster, J. Organomet. Chem., 2013, 724, 102.

23 A. F. Lagalante, B. N. Hansen, T. J. Bruno and R. E. Sievers, Inorg. Chem., 1995, 34, 5781.

24 R. Saravanakumar, B. Varghese and S. Sankararaman, J. Mol. Struct., 2014, 1076, 280.

25 Y.-F. Xiao, T.-T. Wang and H.-P. Zeng, J. Mol. Struct., 2014, 1074, 330 .

26 O. K. Farha, I. Eryazici, N. C. Jeong, B. G. Hauser, C. E. Wilmer, A. A. Sarjeant, R. Q. Snurr, S. T. Nguyen, A. Ö. Yazaydin and J. T. Hupp, J. Am. Chem. Soc., 2012, 134, 15016.

27 M. J. Plater, M. R. S. J. Foremanm and A. M. Z. Slawin, Inorg. Chim. Acta, 2000, 303, 132.

28 Y. Dong, M. D. Smith, R. C. Layland and H. Loye, Inorg. Chem., 1999, 38, 5027.

29 A. Pichon and S. L. James, Cryst. Eng. Commun., 2008, 10, 1839.

30 S. Shu and X. Yuanzhi, Chin. J. Struct. Chem., 1985, 4, 38. 